Thorax (1972), 27, 713.

\title{
Sulphasalazine induced lung disease
}

\author{
G. R. JONES and D. N. S. MALONE \\ Department of Respiratory Diseases, City Hospital, Edinburgh
}

\begin{abstract}
Sulphasalazine is a drug which is widely used in the treatment of ulcerative colitis. Although a high incidence of side effects has been reported, pulmonary complications of treatment have not been described previously. The clinical, haematological, and radiological abnormalities which occurred in one patient two months after sulphasalazine was started are described. Withdrawal of treatment was followed by recovery; reintroduction of the drug caused a relapse associated with eosinophilia and impaired pulmonary function.

We suggest that the possibility of drug-induced lung disease should be considered in any patient who develops symptoms or radiographic evidence of pulmonary disease while receiving treatment with sulphasalazine.
\end{abstract}

Sulphasalazine (Salazopyrin) is widely used in the treatment of ulcerative colitis. Side effects are common and include nausea, vomiting, headache, skin rashes, fever, joint pains, agranulocytosis, haemolytic anaemia, and jaundice (Passmore and Robson, 1970 ; Beeson and McDermott, 1971). Hitherto, pulmonary lesions have not been described.

We report a case of lung disease attributable to sulphasalazine hypersensitivity, confirmed by challenge tests, with serial radiographs and detailed pulmonary function studies.

\section{CASE REPORT}

A.Y., a 36-year-old housewife, was well until August 1970 , when she developed watery diarrhoea three or four times daily; the faeces became bloodstained three months later. Her previous health had been good apart from a mastoid operation in 1963 and an isolated attack of acute bronchitis which responded to tetracycline during the winter of 1969. She stated that aspirin caused her face to swell. Apart from slight generalized abdominal tenderness clinical examination was negative.

Sigmoidoscopy carried out in February 1971 was normal to $27 \mathrm{~cm}$, but a barium enema revealed extensive changes consistent with ulcerative colitis involving the whole colon. Treatment was started with oral sulphasalazine, $4.0 \mathrm{~g}$ daily, propantheline, $15 \mathrm{mg}$ three times daily, and phenobarbitone. Within a month she was much improved and the diarrhoea had ceased, whereupon the phenobarbitone was discontinued.

In April 1971, after two months of treatment, the patient developed a cough productive of frothy mucoid sputum, especially troublesome at night, and increasing exertional dyspnoea with a sensation of chest tightness; wheeze was not present but she felt unable to inspire deeply. Although the bowel symptoms remained well controlled, there had been a loss of $5 \mathrm{lb}(2.3 \mathrm{~kg})$ in weight without obvious cause. There were no abnormal physical signs in the chest, but a chest radiograph on 19 April 1971 showed a fan-shaped opacity in the left lower zone, interpreted as infective in origin. Ampicillin, $1.0 \mathrm{~g}$ daily, followed by oxytetracycline, $1.0 \mathrm{~g}$ daily, was prescribed and this treatment was continued for one month but the symptoms progressed. A second radiograph on 20 May showed widespread infiltrative opacities throughout the left lung and also in the right upper lobe (Fig. 1).

The patient was admitted to hospital on 21 May when clinical examination was negative except for a remittent fever of $101^{\circ} \mathrm{F}\left(38^{\circ} \mathrm{C}\right)$ and a persistent sinus tachycardia. The results of investigations were as follows:

Haemoglobin $9.9 \mathrm{~g} \%$, normochromic normocytic anaemia; WBC $5,000 / \mathrm{mm}^{3}$, neutrophils $43 \%$, lymphocytes $52 \%$, and monocytes $5 \%$; ESR $110 \mathrm{~mm} /$ hour. The sputum did not contain pathogenic bacteria or aspergilli, and the urine was normal. The Mantoux test 1:1,000 dilution was positive. No tubercle bacilli were cultured from sputum or faeces. Blood cultures, precipitin tests for aspergillus and brucella, and antibody titres for viruses and mycoplasma were negative. Blood urea, serum electrolytes, and liver function tests were all normal, and tests for antinuclear factor were negative on numerous occasions.

While investigation was proceeding, treatment with sulphasalazine and propantheline was continued. Ferrous gluconate, $300 \mathrm{mg}$ three times daily, and a sevenday course of ampicillin, $500 \mathrm{mg}$ four times daily, was also given from 4 to 11 June without improvement. This was followed by a 10-day trial of antituberculosis chemotherapy using streptomycin $(0.75 \mathrm{~g}$ i.m. daily), isoniazid $(200 \mathrm{mg}$ daily) and ethambutol $(1 \cdot 1 \mathrm{~g}$ daily) (PAS was avoided in view of the previous bowel pro- 


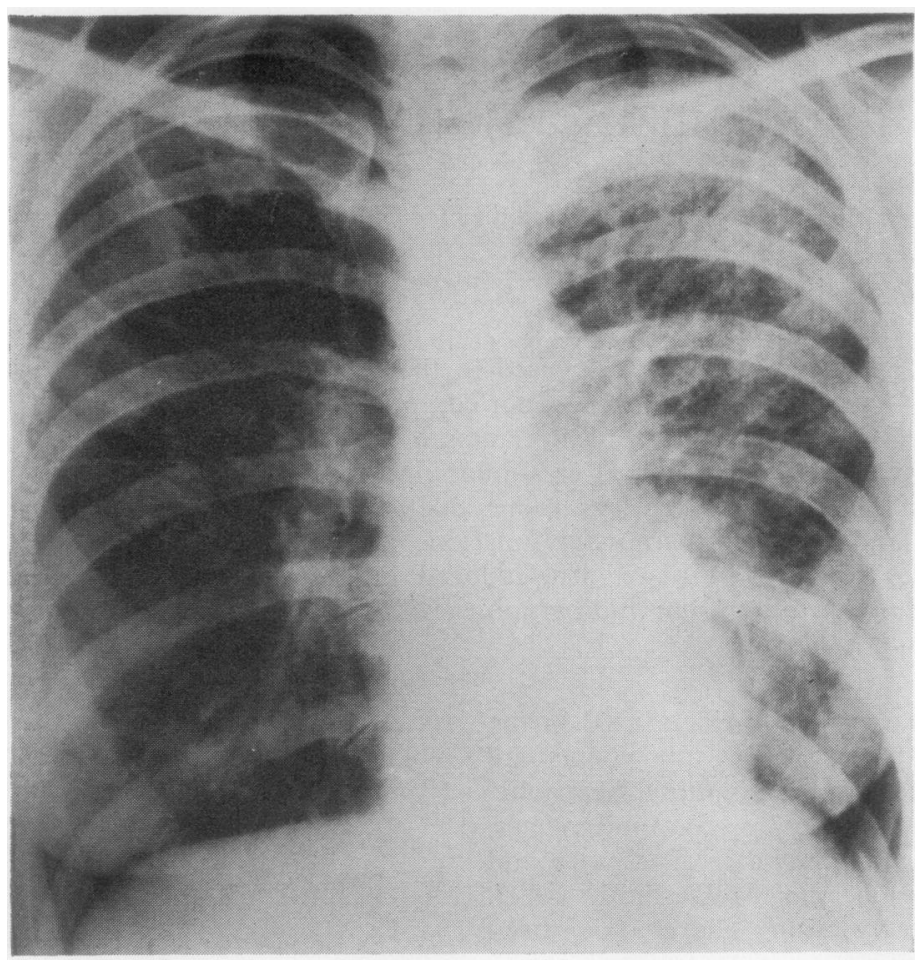

FIG. 1. Radiograph (20 May 1971) before investigation, showing numerous opacities in the left lung and in the right upper lobe.

T A B LE I

\begin{tabular}{|c|c|c|c|c|c|c|c|c|c|c|c|c|c|c|c|c|}
\hline & & & \multirow{2}{*}{$\begin{array}{l}\text { Normal Range } \\
\text { or Predicted } \\
\quad( \pm \mathbf{S D})\end{array}$} & \multicolumn{13}{|c|}{ Days after Onset of Exposure to Sulphasalazine (1 Sept. 1971) } \\
\hline & & & & 0 & 1 & 2 & 3 & 4 & 5 & 6 & 7 & $8^{2}$ & 9 & 10 & 12 & 28 \\
\hline $\begin{array}{l}\text { Sulphasalazine (g) } \\
\text { Symptoms }\end{array}$ & . & $\begin{array}{l}\cdots \\
\cdots\end{array}$ & \multirow[b]{2}{*}{$\begin{array}{c}4,000-10,000 \\
0-\quad 400\end{array}$} & 0 & 0.5 & $1 \cdot 0$ & 1.5 & $2 \cdot 0$ & $2 \cdot 5$ & $3 \cdot 0$ & $\begin{array}{l}2 \cdot 0^{1} \\
\text { Dysp- } \\
\text { noea }\end{array}$ & 3.5 & \multirow{2}{*}{\begin{tabular}{l}
\multicolumn{1}{c}{0} \\
Cough \\
\& Dysp- \\
noea \\
Abn \\
\\
\\
\\
1
\end{tabular}} & 0 & \multirow{2}{*}{$\begin{array}{c}\text { 0 } \\
\text { Dysp- } \\
\text { noea } \\
\text { Abn }\end{array}$} & \multirow[t]{2}{*}{0} \\
\hline $\begin{array}{l}\text { Chest radiograph } \\
\text { Total WBC }\left(\mathrm{mm}^{3}\right) \\
\text { Eosinophils }\left(\mathrm{mm}^{3}\right)\end{array}$ & $\begin{array}{l}\cdots \\
\therefore\end{array}$ & $\begin{array}{l}\cdots \\
\cdots\end{array}$ & & $\begin{array}{c}N \\
5,700 \\
285\end{array}$ & & $\begin{array}{c}\mathrm{N} \\
5,200 \\
260\end{array}$ & & & & $\begin{array}{r}5,800 \\
696\end{array}$ & Abn & & & $\begin{array}{l}8,000 \\
1,090\end{array}$ & & \\
\hline 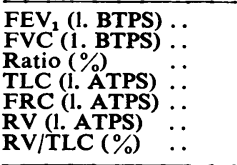 & $\begin{array}{l}\cdots \\
\therefore \\
\therefore \\
\therefore \\
\therefore\end{array}$ & $\begin{array}{l}\cdots \\
\therefore \\
\therefore \\
\therefore \\
\therefore\end{array}$ & $\begin{aligned} 2 \cdot 8 & \pm 0 \cdot 4 \\
3 \cdot 5 & \pm 0 \cdot 4 \\
83 & \pm 5 \\
4 \cdot 7 & \pm 0 \cdot 5 \\
2 \cdot 3 & \pm 0 \cdot 4 \\
1 \cdot 5 & \pm 0 \cdot 4 \\
32 & \pm 6\end{aligned}$ & \begin{tabular}{|c|}
$2 \cdot 9$ \\
$3 \cdot 9$ \\
75 \\
$5 \cdot 2$ \\
3.4 \\
1.6 \\
31
\end{tabular} & $\begin{array}{c}3 \cdot 0 \\
4 \cdot 1 \\
74 \\
5 \cdot 2 \\
3 \cdot 4 \\
1 \cdot 5 \\
29\end{array}$ & $\begin{array}{l}3 \cdot 0 \\
4 \cdot 0 \\
75\end{array}$ & $\begin{array}{c}3 \cdot 0 \\
4 \cdot 0 \\
75 \\
5 \cdot 2 \\
3 \cdot 3 \\
1 \cdot 7 \\
33\end{array}$ & & $\begin{array}{r}2 \cdot 4 \\
3 \cdot 6 \\
67 \\
5 \cdot 2 \\
3 \cdot 3 \\
1 \cdot 9 \\
37\end{array}$ & & $\begin{aligned} 2 \cdot 6 \\
3 \cdot 6 \\
71 \\
5 \cdot 2 \\
3 \cdot 5 \\
2 \cdot 0 \\
40\end{aligned}$ & $\begin{array}{c}2 \cdot 2 \\
3 \cdot 4 \\
65\end{array}$ & $\begin{array}{ll}2 \cdot 7 \\
75 & \\
75 & 6\end{array}$ & $\begin{array}{r}2 \cdot 3 \\
3 \cdot 5 \\
66\end{array}$ & $\begin{array}{c}2 \cdot 9 \\
3 \cdot 7 \\
77 \\
5 \cdot 3 \\
3 \cdot 4 \\
1 \cdot 7 \\
32 \\
\end{array}$ & $\begin{array}{r}3 \cdot 4 \\
3 \cdot 7 \\
92 \\
5 \cdot 4 \\
3 \cdot 6 \\
1 \cdot 7 \\
32 \\
\end{array}$ \\
\hline \multicolumn{2}{|l|}{ TF SB (ml/min $/ \mathrm{mmHg})$} & .. & $28 \pm 3$ & 21 & 19 & & 19 & & 17 & & 16 & & & & 18 & 21 \\
\hline 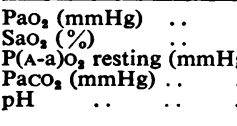 & & $\begin{array}{l}. \\
\therefore \\
\cdots \\
\therefore\end{array}$ & $\begin{array}{cc}93 & \pm 7 \\
>95 & \\
10 & -15 \\
36 & -44 \\
7 \cdot 36-7 \cdot 44\end{array}$ & $\begin{array}{l}97 \\
96 \\
16 \\
35 \\
7 \cdot 45\end{array}$ & & & & & & & $\begin{array}{l}87 \\
97 \\
26 \\
38 \\
7 \cdot 55\end{array}$ & $\begin{array}{l}83 \\
38 \\
7 \cdot 42\end{array}$ & $\begin{array}{l}87 \\
97 \\
23 \\
37 \\
7 \cdot 55\end{array}$ & & & \\
\hline \multicolumn{17}{|c|}{$\begin{array}{l}\text { Abn = abnormal. } N=\text { normal. } \\
\text { error. }{ }^{2} \text { Drug withdrawn. }\end{array}$} \\
\hline
\end{tabular}




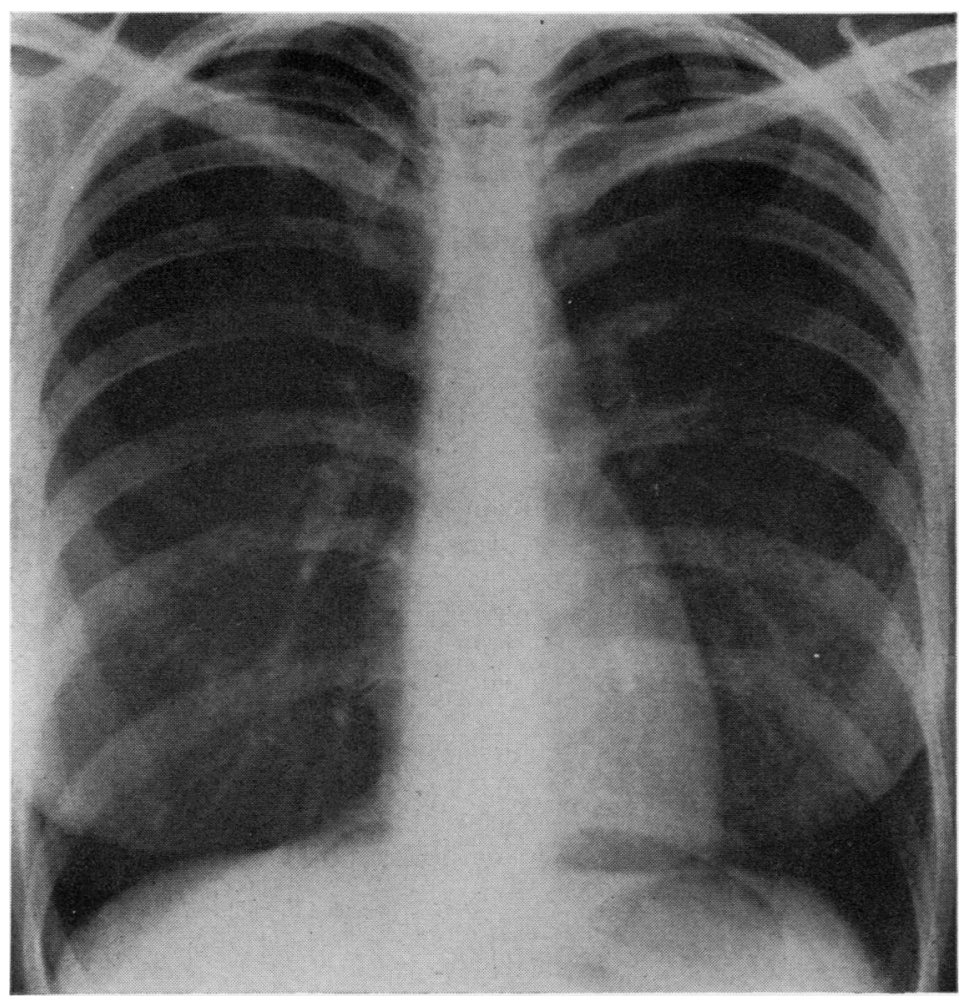

FIG. 2. Normal radiograph (30 Aug. 1971) before challenge test.

blems), again without any effect on the symptoms, fever, or chest radiographs. At this stage, peripheral blood eosinophilia $\left(750 / \mathrm{mm}^{3}\right)$ was noted and the possibility of drug hypersensitivity was considered.

Consequently all therapy was discontinued on 21 June and within five days the temperature was normal, the tachycardia had settled, and there was rapid disappearance of cough, sputum, and dyspnoea. The chest radiograph on 28 June showed almost complete clearing, the only residua being a few linear opacities in the upper zones. The ESR fell to $12 \mathrm{~mm} /$ hour. Unfortunately, troublesome bowel symptoms returned within eight weeks of stopping sulphasalazine and propantheline. It was therefore decided to evaluate objectively the possible role of sulphasalazine in the aetiology of the pulmonary disease.

Base line measurements of full blood count, ventilatory capacity, lung volumes, carbon monoxide transfer factor, and arterial blood gases were made. The only significant abnormality was a reduced transfer factor (Table I). A chest radiograph was normal (Fig. 2). Progressive exercise testing using a bicycle ergometer was also performed, and the results are shown in Table II. The patient was then challenged with sulphasalazine starting with a dose of $0.5 \mathrm{~g}$
T A B L E I I

RESPONSE TO PROGRESSIVE EXERCISE

\begin{tabular}{|c|c|c|c|c|}
\hline \multirow[b]{2}{*}{$\begin{array}{l}\text { Work load (kpm/min) } \\
\text { Heart rate (beats/min) } \\
\text { Frequency (breaths/min) } \\
\text { Ventilation (litres } / \mathrm{min}) \\
\text { Tidal volume (ml/min) } \\
\text { Carbon dioxide production } \\
\text { Oxygen consumption (ml/n }\end{array}$} & \multirow[b]{2}{*}{ 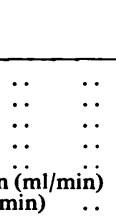 } & \multirow{2}{*}{ 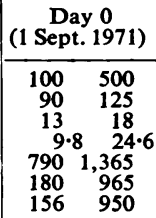 } & \multicolumn{2}{|c|}{$\underset{\text { Day } 7}{\text { (8 Sept. 1971) }}$} \\
\hline & & & $\begin{array}{l}100 \\
110 \\
12 \\
10 \cdot 6 \\
775 \\
359 \\
432\end{array}$ & $\begin{array}{c}500 \\
156 \\
23 \\
29 \cdot 7 \\
1,285 \\
1,145 \\
1,082\end{array}$ \\
\hline
\end{tabular}

orally on 1 September and increasing by this amount daily. On day 5 , when the dose was $2.5 \mathrm{~g}$, a fall in forced expiratory volume in the first second $\left(F E V_{1}\right)$, forced vital capacity (FVC), and FEV / FVC occurred, followed the next day by a blood eosinophilia. By day 7 , the patient was aware of mild dyspnoea; the transfer factor had fallen and the alveolar-arterial oxygen difference $\left(\mathrm{P}(\mathrm{A}-\mathrm{a}) \mathrm{O}_{2}\right)$ at rest had increased. Exercise tolerance was again studied by progressive exercise testing (Table II). Sulphasalazine was discontinued on day 8 , by which time the patient had developed a cough in addition to dyspnoea; the $F E V_{1}$, $F V C$, and $F E V_{1} / F V C$ had decreased further. $A$ repeat 


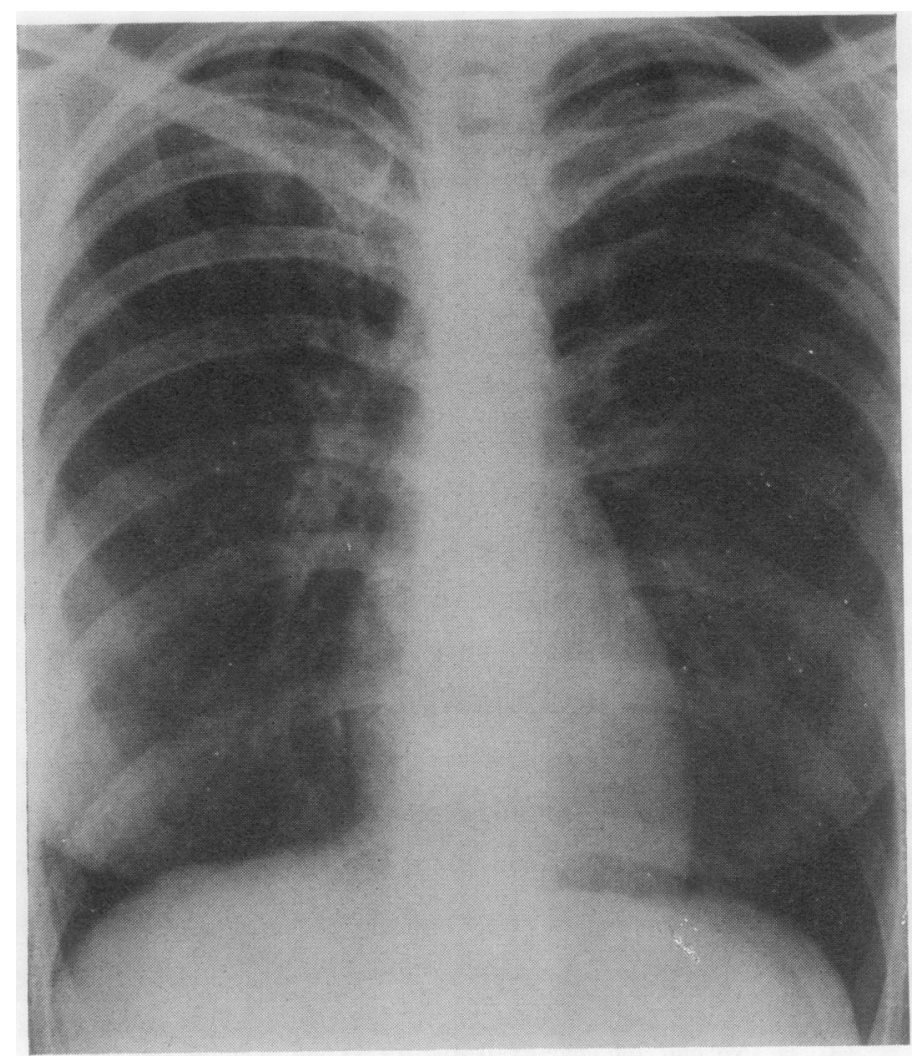

FIG. 3. Radiograph (10 Sept. 1971) following. challenge test, showing recurrence of opacities in right upper lobe.

radiograph revealed an opacity in the right upper lobe (Fig. 3), and the blood eosinophilia had increased to $1,090 / \mathrm{mm}^{3}$. At no time during the challenge was there any fever. Over the next few days symptoms abated, ventilatory function and transfer factor returned to previous levels, and by day 28 (29 September) the chest radiograph was normal.

There is no doubt that the patient's ulcerative colitis responded well to sulphasalazine and propantheline. However, following the allergic pulmonary reaction to sulphasalazine there was residual impairment of the transfer factor for carbon monoxide. It was therefore considered unwise to attempt hyposensitization to this drug. The patient was instructed to avoid sulphasalazine as well as other sulphonamides and salicylates in future. Subsequently it became necessary to embark on alternative therapy for the ulcerative colitis, which included oral corticosteroids.

\section{DISCUSSION}

Sulphasalazine is an absorbed diazo compound which is split in the tissues to sulphapyridine and 5-aminosalicylic acid (Passmore and Robson,
1970). Pulmonary lesions have been described due to aspirin (Ford, 1966) and sulphonamides (Fiegenberg, Weiss, and Krishman, 1967), the reaction to the former being distinct from aspirin-induced asthma (Samter and Beers, 1968). The syndrome produced by these drugs closely resembles simple pulmonary eosinophilia: a cough productive of mucoid sputum which may contain eosinophils, often without fever, is accompanied by characteristic radiographic appearances of fairly homogeneous fan-shaped opacities with indefinite borders, and a moderate blood eosinophilia, but frequently without significant clinical findings in the chest (Crofton and Douglas, 1969). Histologically the alveoli contain numerous histiocytes and eosinophils in a protein-rich oedema, but, apart from a mild perivasculitis, the pulmonary interstitial tissue is not involved (Fiegenberg et al., 1967). While the exact nature of the allergic mechanism is not known (Davies, 1969) it is obvious that either or both constituents of sulphasalazine might be responsible for the pulmonary lesions in 
this patient, and the previous history of allergy to aspirin may be relevant.

ROUTINE PULMONARY FUNCTION TESTS (Table I) Before challenge with sulphasalazine the only demonstrable abnormality of pulmonary function was a low carbon monoxide transfer factor. As the drug dosage was gradually increased impairment of ventilatory capacity occurred with reduction in both $F E V_{1}$ and FVC, although the decrease in the former was proportionately greater, as evidenced by the fall in $F E V_{1} / F V C$. The ratio of residual volume to total lung capacity increased steadily. These abnormalities were indicative of mild airways obstruction although there was no clinical evidence of this.

Over the same period of observation a stepwise reduction in transfer factor occurred; resting $\mathrm{PaO}_{2}$ fell by $14 \mathrm{mmHg}$ and $\mathrm{P}(\mathrm{A}-\mathrm{a}) \mathrm{O}_{2}$ at rest increased to $26 \mathrm{mmHg}$. These changes were consistent with maldistribution of ventilation and perfusion leading to impaired gas exchange.

RESPONSE TO EXERCISE (Table II) On both occasions on which this was studied the patient's performance was impaired in that a work load of $500 \mathrm{kpm} / \mathrm{min}$ was the maximum tolerated because of inability to pedal further. When the results of the two tests are compared, the only appreciable change was an increase in the minute ventilation on day 7. This was achieved by an increased rate of breathing without any rise in tidal volume, a change which is commonly associated with restrictive lung disorders. There was also tachycardia and increased oxygen consumption and carbon dioxide production, all of which might have been attributable to increased work of breathing. At no time during or following progressive exercise did the patient develop any wheeze.

The incidence of nausea, vomiting, and headache with sulphasalazine therapy has been variably reported as 15 to $20 \%$ (Spriggs, Smith, Griffith, and Truelove, 1958) and 45 to $65 \%$ (Conn, 1971). Skin rashes, febrile reactions, and joint pains are less common, and agranulocytosis, haemolytic anaemia, and jaundice are rare (Beeson and McDermott, 1971). Neurotoxicity has also been reported by Wallace (1970). Despite the wide use of sulphasalazine in ulcerative colitis, pulmonary lesions due to the drug have not been described previously. While it remains invaluable in the control and treatment of this debilitating disease, sulphasalazine should be used with caution when there is a history of allergy to aspirin or sulphonamides. Furthermore, mild respiratory symptoms developing in such patients merit further investigation.

We wish to thank Dr. J. W. Fraser and Dr. A. C. Douglas for allowing us to study their patient, Dr. G. J. R. McHardy for his advice, and Miss Sylvia Merchant and Mrs. Lynda Scott for their help.

\section{REFERENCES}

Beeson, P. B., and McDermott, W., Eds. (1971). Cecil-Loeb Textbook of Medicine. W. B. Saunders, Philadelphia, London and Toronto.

Conn, H. F. (Ed.) (1971). Current Therapy. W. B. Saunders, Philadelphia, London and Toronto.

Crofton, J. W., and Douglas, A. (1969). Respiratory Diseases. Blackwell, Oxford and Edinburgh.

Davies, P. D. B. (1969). Drug-induced lung disease. Brit. J. Dis. Chest, 63, 57.

Fiegenberg, D. S., Weiss, H., and Krishman, H. (1967). Migratory pneumonia with eosinophilia associated with sulfonamide administration. Arch. intern. Med., 120, 85.

Ford, R. M. (1966). Transient pulmonary eosinophilia and asthma. A review of 20 cases occurring in 5,702 asthma sufferers. Amer. Rev. resp. Dis., 93, 797.

Passmore, R., and Robson, J. S., Eds. (1970). A Companion to Medical Studies, Vol. 2. Blackwell, Oxford and Edinburgh.

Samter, M., and Beers, R. F. (1968). Intolerance to aspirin. Clinical studies and consideration of its pathogenesis. Ann. intern. med., 68, 975.

Spriggs, A. I., Smith, R. S., Griffith, H., and Truelove, S. C. (1958). Heinz-Body anaemia due to salicylazosulphapyridine. Lancet, 1, 1039.

Wallace, I. W. (1970). Neurotoxicity associated with a reaction to sulphasalazine. Practitioner, 204, 850. 